\title{
Effectiveness of Self Instructional Information on Knowledge of Office Ergonomics among Computer Users in Educational Institutions in Nigeria
}

\author{
Sokunbi Ganiyu $(\mathrm{PhD})^{1 *}$, Gabriel George $(\mathrm{BMR})^{2}$ \\ Department of Medical Rehabilitation, College of Medical Sciences, University of Maiduguri, Maiduguri \\ Nigeria \\ Department of Medical Rehabilitation, College of Medical Sciences University of Maiduguri, Maiduguri, \\ Nigeria
}

\begin{abstract}
:
Objectives: The purpose of this study is to assess the effectiveness of self-instructional information on knowledge regarding office ergonomics among computer users.

Methods: 170 computer users among the staffs of selected higher educational institutions in Nigeria participated in this study. Occupational Safety and Health Administration (OSHA) workstation checklist was used to assess the level of knowledge of office ergonomics. Work Safely with Visual Display Terminal (WSVDT) booklet was used to provide instructional information on office ergonomics. Both OSHA and WSVDT were administered and collected by hand. Paired t-test and Kendall's correlation coefficients were used for data analysis. Statistical significance was set at alpha level of 0.05

Results: The pre-information and post-information knowledge scores of office ergonomics were $22.78 \pm 6.61$ and $31.05 \pm 2.82$ respectively. Paired $t$ test showed a significant difference in the pre information and post information knowledge scores of the participants $(t=20.495, P$ value $=0.000)$. Kendall's correlation coefficient value $(r)$ of the association between changes in the level of knowledge of office computer ergonomics and each of age, level of education of computer users, levels of computer use; i.e. daily computer use, weekly computer use and total period of computer use were -0.28, 0.34, 0.59, 0.24 and 0.07 respectively. Age did not show statistical significant correlation with changes in the knowledge of office ergonomics $(P>0.05)$ which was present in the level of educational qualifications and all levels of duration of computer use $(P<0.05)$.

Conclusion: Findings from this study showed that instructional information on computer office ergonomics increase the level of knowledge of office ergonomics among computer users in selected institution of learning in Nigeria. It also showed that level of education and duration of computer use increase with increase in the changes in the level of knowledge of computer office ergonomics among computer users.
\end{abstract}

Key words: Computerusers, Office-ergonomics, Training

\section{Introduction}

Computers provide many benefits to organizations as they allow the processing, storage, generation and communication of vast amounts of data quickly and accurately, resulting in increased efficiency and productivity ${ }^{1}$ During the past years computers have gone from being scarce in various institutions of learning to being a standard part of the day-to-day running of academic and non-academic programs. Much funding has gone towards obtaining computers for staff within Nigerian universities and other Institutions of learning, without corresponding infrastructure support and training for the users. Ergonomics is the science of fitting jobs to workers by taking into account the requirements of the job and peoples' physical and mental capacities ${ }^{2}$. It is the science of ergonomics that is used to design an appropriate computer workstation. When workstations are not designed appropriately, when non-ergonomically designed computer equipment is used and when jobs and tasks are not well organized, a number of computer related health problems can arise ${ }^{3}$. Whether browsing the web or intensively entering and editing text in a document, arms, wrists, and fingers are at work on the keyboard, mouse, and desktop. These continuous movements cause repetitive strain injury (RSI). Reports of studies have suggested clearly the likelihood of suffering health problems linked to computer use is related to the amount of time spent using them and also lack of knowledge related to computer ergonomics. There is evidence that computer related musculoskeletal symptoms can be reduced through an ergonomics approach and through education ${ }^{2}$.The important question is whether the alleged planned teaching program on ergonomics for computer use will be effective in increasing the level of knowledge of office ergonomics among computer users 


\section{Materials And Methods}

\section{Ethical approval}

Permission to carry out this study was obtained from Research and Ethics Committee of University of Maiduguri Teaching Hospital. Detail information about the study was provided and informed consent was obtained from the participants prior to participating in the study.

Questions on demographic variables such as age, sex, level of education, duration of computer usage were collected via a well-structured questionnaire.

\section{Participants}

Participants were computer users and staffs of the University of Maiduguri (UNIMAID), University of Maiduguri Teaching Hospital (UMTH), Ramat Polytechnic and Kashim Ibrahim College of Education Maiduguri. Eligible participants were those who were using desktop and/or or laptop computers, able to read, write and understand English language.Computer users who met these criteria but have undergone any similar studies previously were excluded.

\section{Assessment of level of knowledge of office ergonomics}

Occupational Safety and Health Administration (OSHA) Workstation checklist was used to assess the level of knowledge of office ergonomics prior to and after administration of instructional information. The OSHA workstation checklist is used specifically for identifying risk factors for work-related MSDs associated with workstation postures and devices. The OSHA workstation checklist revealed specific risks for work-related musculoskeletal disorders (MSDs) related to positioning of the head, neck, shoulders, and trunk, as well as seating issues. The workstation checklist also identifies risks associated with keyboard and mouse position, monitor position, and lack of document holder, wrist rests, and telephone hands-free headset. OSHA workstation checklist is made up of 34 different statements where participants will be required to respond to each of the statement by indicating either Yes or No. A score of 1 was assigned to a correct response and 0 to an incorrect response. It has been shown to have good internal consistency $(\alpha=.89)$ and good test-retest reliability $(r=.88)$ and is correlated with measures of pain $(r=.41)$ and upper-extremity symptoms $(r=.33)^{3}$

\section{Instructional information materials on office ergonomics}

Work Safely with Visual Display Terminal (WSVDT) booklet was used to provide instructional information on office ergonomics. It is a self-instructional information booklet on office ergonomic problems and its management: This booklet examines the potential hazards and interventions employers can use to prevent or reduce the potential harmful effects of working with Visual display terminals (VDTs). The information in this booklet comes from standard office practice guidelines for tasks requiring long periods of concentrations and repetitive motions among computer users. These suggestions will help users to avoid fatigue and discomfort and tell them how to best use the computer to make tasks easier and more enjoyable ${ }^{1}$.

\section{Procedure}

Prior to administering instructional information material on office ergonomics, OSHA workstation checklist was administered to all the participants who were then requested to complete and returned it immediately. Following this, an instructional information material on office ergonomics, WSVDT was given to all the participants who were then requested to study it within 24hrs (1 day). Upon returning the WSVDT, OSHA workstation check list was then re-administered to the participants for immediate completion. Administration and collection of questionnaires and instructional information material was done by hand.

\section{Data analysis}

Paired t-test was used to analyse the differences between pre-information and post information level of knowledge scores. Kendall's Correlation Coefficient was used to determine the association between changes in the level of knowledge and each of the demographic variable such as age, level of educational qualification and duration of computer use. The level of significance will be set at alpha $=0.05$

\section{Results}

One hundred and seventy copies of Occupational Safety and Health Administration (OSHA) VDT Workstation Checklist questionnaire were distributed. One hundred and seventy were returned, giving a response rate of $100 \%$. All the returned questionnaires were included in the analysis process.

Table 1 shows the socio-demographic variables of the participants; age, gender, level of education and period of computer usage. A total number of one hundred and seventy (170) participants between the ages of $15 y e a r s$ above met the inclusion criteria and were recruited into the study and were grouped into four groups i.e. $15-24,25-34,35-44$, and 45years above. Numbers of participants between the ages of 15-44 were 123 (72.4\%), participants from 45 years of age and above were 47 (27.6\%). Majority of the participants, 112 
(65.9\%) were male and 58 (34.1\%) were female. Participants with primary/elementary school to secondary/high school qualifications were 67(39.4\%), and participants with bachelor degree qualification and above were 103 (60.6\%). 128 (75.3\%) Participants who work with computer between less than one hour to four hours, and participants who work with computer from five hours and above daily were $42(24.7 \%) .45(26.4 \%)$ of the participants use computer within once to four times weekly and 125 (73.5\%) use computer five times and above on weekly basis. In terms of participants' total period of computer use, those who have used computer for less than to three years were $21(12.3 \%)$, and participants who used computer between four years and above were 25 $(14.7 \%)$.

Table 2 shows the pre-information and post-information knowledge scores of the participants. The pre information scores have a mean and standard deviation value of $22.78 \pm 6.61$. While the post information knowledge scores was $31.05 \pm 2.82$. However, paired t-test showed a significant difference between preinformation and post-information knowledge scores of the participants $(\mathrm{t}=20.495, \mathrm{P}$ value $=0.000)$.

Table 3 shows Kendall's Correlation Coefficient on the association between age, level of education, daily computer, weekly computer, total period of computer use and changes in the level of knowledge of office ergonomic (post-information knowledge scores minus pre-information knowledge scores) of the participants. The coefficient value (r) between changes in the level of knowledge and each of age, level of education, daily computer use, weekly computer use and total period of computer use were $-0.28,0.34,0.59,0.24$ and 0.07 respectively. Age did not show statistical significant correlation with changes in the knowledge of office ergonomics $(\mathrm{P}>0.05)$ which was present in the level of educational qualifications and duration of computer use $(\mathrm{P}<0.05)$.

\section{Discussion}

Findings from this study establish that the information module on office ergonomics increased the participants' level of knowledge on office ergonomics among computer users in the selected institutions of higher learning. This is very important to note as previous studies have revealed lack of knowledge of office ergonomics as one of the risk factors for developing computer related musculoskeletal disorders. Omokhodion and Sanya ${ }^{4}$ carried out a study on ergonomic practices and musculoskeletal complaints among office computer users, their study revealed poor computer ergonomics practice, lack of training of computer users and nonavailability of policies on computer ergonomics. The findings from this present study has shown that instructional information on office ergonomics could be a means of empowering computer users on computer ergonomic principles, so as to prevent the occurrence of work-related MSD's that could arise from improper use of computers.

The outcome of this present study showed negative correlation between age of computer users and positive changes in the level of knowledge of office ergonomics. This could mean that the younger computer users demonstrated more understanding of the information provided than the older computer users. Conversely, levels of education and duration of computer use showed positive correlations to the changes in the level of knowledge of office ergonomics as results of the information modules provided. This perhaps could imply computer users who spent more time using computer and those who were more educationally qualified demonstrated more understanding of the information provided on office ergonomics. It appears that studies on the association between age and level of education of computer users with information on office ergonomics are scarce and thus limiting comparison of the findings from this study with previous ones. However reports of some previous reviews have indicated a possible causal relationship between computer work and musculoskeletal complaints in various parts of the human body ${ }^{5.6 .7}$. In these studies, the increase prevalence has been linked to factors such as duration of daily keyboard and mouse usage, poor workstation design, and assumed posture during computer work ${ }^{8}$. Bart ${ }^{9}$ reported the association between prolonged computer uses, poor postures at workstations as the main cause of musculoskeletal disorder. Hatkala ${ }^{10}$ suggest that prolonged selfreported computer usage is the most consistently reported risk factor for computing related musculoskeletal disorders across study populations. In many instances among regular computer user's different parts of the body especially the wrist is usually forced into an unnatural position. As a result of this there is an increased workload for the small muscles in the hand and the muscles that bend the fingers and stabilize the wrist. Also, there is a harmful load for the tendons and joints in the hand and wrist coupled with the risk of nerve compression and increased static muscular strain in the muscles in different part of the body to compensate for the distorted work position ${ }^{11}$. Static compression of the muscle compresses the blood vessels and thus reduces blood flow to the muscles. The supply of oxygen and energy is reduced while the waste products of the working muscle accumulate in the muscles. These wastes hasten muscle fatigue and can eventually cause pain, hardening, and cramps $^{11}$.

Since many shoulder muscles act to stabilise the shoulder girdle joints, arm work which might seem dynamic might entail static shoulder muscle activity as well. Neck and shoulder discomfort could also be influenced in a complicated way by load moment induced by the arms, by the forces applied in the hands and by 
moment induced by weight of head and neck during computer use. Petrofsky and Phillips ${ }^{12}$ reported that 2 to $5 \%$ of a maximum voluntary contraction (MVC) in the upper trapezius causes a sign of fatigue if maintained for an hour, and this contraction level is easily reached by shoulder flexion and abduction even without loading the arm. In addition the demands on precision, speed and concentration during computer use could raise the psychological stress level and add further stress to that induced by static muscle load and repetitive strain discomfort.

The observed increase in the level of knowledge of office ergonomics could be due to the facts that majority of the participants who also, are regular computer users lacks the knowledge of basic office ergonomics prior to reading the information pamphlet. It could also mean that majority of the computer users in the present study via the information provided became aware of the consequences of assuming poor posture while using the computer as they read about it in the booklet and looked at illustrations on correct and incorrect postures and consequences of adopting incorrect postures as presented in the present study. Ming and Zaproudina ${ }^{13}$ andWahlstrom ${ }^{14}$ in their studies indicated various parts of the body including neck, shoulder, back, and leg, as where computer users could have musculoskeletal complaints as a result of poor computer ergonomics. Thus, it could be that instructional information material which contain information on deleterious effects of adopting poor working posture and also diagram (pictorial illustrations) showing right and wrong postures in these different part of the body have been very useful to enhance understanding of the participants on office ergonomics. However, there will be a need for large randomised controlled trials involving larger number of subjects and in which the effects of such instructional information modules on the incidence, intensity and /or frequency of work related MSD's among computer users to validate the perceived benefits of the instructional information.

\section{Conclusion}

This study concluded that information module on computer office ergonomics increase the level of knowledge of office ergonomics among computer users in selected institution of learning in Nigeria. It also showed that level of education and duration of computer use increase with changes in the level of knowledge of computer office ergonomics.

\section{References}

[1] Bergvis, U,Sotoyama M, Saito, S, Piccoli B. Computer in Schools, an international project under planning 1997 [Cited at 2014 , August 15]. Available from http//tmc03.human.waseda.ac.jp/wwdu97/PrcHp

[2] Computer Workstation Ergonomics: A Guide for UMNDJ Computer Users 2008. Environmental \& Occupational Health \& Safety Services

[3] OSHA W-1 Basic Screening Tool. Occupational Safety and Health Administration [cited at 2014 August 15]. Available fromhttp://www.osha.gov.

[4] Omokhodion, FO, and Sanya, AO. Risk factors for low back pain among office workers in Ibadan, southwest Nigeria. Occupational Medicine, 2003 53: 87-289

[5] Woods V. 2005. Musculoskeletal disorders and visual strain in intensive data processing workers. Occupational Medicine, 2005, 55:121-127.

[6] Janwantanakul P, Praneet P, Jiamjarasrangsri V. and Sinsongsook, T. Prevalence of self- reported musculoskeletal symptoms among office workers. Occupational Medicine 2008 58: 436- 438.

[7] Klussmann, A, Gebhardt H, Liebers F and Rieger, M A. Musculoskeletal symptoms of the upper extremities and the neck: A crosssectional study on prevalence and symptom-predicting factors at visual display terminal workstations. BMC Musculoskeletal Disorders, 2008 9(96): 1-16.

[8] Kryger, AI, Andersen JH, Lassen, CF, Brandt LP, Vilstrup I, Overgaard E, Thomse JF, and Mikkelsen S,. Does computer use pose an occupational hazard for forearm pain; from the NUDATA study, Occupational and Environmental Medicine 2003, 60, p. 14.

[9] Bart NG. "A literature review of neck pain associated with computer use: public health implications".J Can Chiropr Assoc. 2008 52(3):161-167.

[10] Hakala P, Rimpela A, Salminen JJ, Virtanen SM, and Rimpela, M, . Back, neck, and shoulder pain in Finnish adolescents: national cross-sectional surveys. BMJ 2002. 325: 743-746.

[11] Margaret IB. Ergonomics: The physiotherapist in the work place. London, Churchill Livingstone, 1990:101-111

[12] Petrofsky JC, and Phillips CA. The strength-endurance relationship in skeletal muscle; Its application to helmet design. Aviation, Space and Environmental Medicine1982. 53; 365-369

[13] Ming Z. and Zaproudina, N. Computer use related upper limb musculoskeletal (ComRULM) disorders. Pathophysiology 2003. 9:155-160

[14] Wahlström J. Ergonomics, musculoskeletal disorders and computer work. Occupational Medicine, 2005. 55:168-176. 
Effectiveness of Self Instructional Information on Knowledge of Office Ergonomics among Compurter

Table 1: Participants Age, Gender, Level of Education and Period of computer usage

\begin{tabular}{|c|c|c|}
\hline Variables & Frequency & Percentage (\%) \\
\hline \multicolumn{3}{|l|}{ Age } \\
\hline $15-24$ years & 10 & 5.9 \\
\hline 25-34years & 60 & 35.3 \\
\hline $35-44$ years & 53 & 31.2 \\
\hline 45years and above & 47 & 27.6 \\
\hline \multicolumn{3}{|l|}{ Gender } \\
\hline Male & 112 & 65.9 \\
\hline Female & 58 & 34.1 \\
\hline \multicolumn{3}{|l|}{ Level of Education } \\
\hline Primary/Elementary School & 3 & 1.8 \\
\hline Secondary/High School & 64 & 37.6 \\
\hline Bachelor Degree & 41 & 24.1 \\
\hline Master Degree & 34 & 20.0 \\
\hline Doctorate Degree & 28 & 16.5 \\
\hline \multicolumn{3}{|l|}{ Daily Computer Use } \\
\hline Less than $1 \mathrm{hr}$ & 10 & 5.9 \\
\hline $1-2 \mathrm{hr}$ & 52 & 30.6 \\
\hline $3-4 \mathrm{hr}$ & 66 & 38.8 \\
\hline $5 \mathrm{hr}$ and above & 42 & 24.7 \\
\hline \multicolumn{3}{|l|}{ Weekly Computer Use } \\
\hline Once weekly & 4 & 2.4 \\
\hline Twice weekly & 13 & 7.6 \\
\hline Thrice weekly & 15 & 8.8 \\
\hline Four times in a week & 13 & 7.6 \\
\hline Five times a week and above & 125 & 73.5 \\
\hline \multicolumn{3}{|l|}{ Total Period of Computer Use } \\
\hline Less than 1year & 5 & 2.9 \\
\hline $2-3$ years & 16 & 9.4 \\
\hline 4-5years & 25 & 14.7 \\
\hline
\end{tabular}

Table 2: Pre information and post information knowledge scores

\begin{tabular}{lccc}
\hline Variables & Mean \pm Std. Deviation t-value & \multicolumn{2}{c}{ P-value } \\
\hline $\begin{array}{l}\text { Pre-information Knowledge score } \\
{[\text { Pre-IK] }}\end{array}$ & $22.78 \pm 6.61$ & & \\
Post-Information Knowledge & $31.05 \pm 2.82$ & 20.495 & $0.000^{*}$ \\
{$[$ Post-IK] } & & & \\
\hline
\end{tabular}

* = significant 